\title{
Hiper IgD syndrome (HIDS): clinical and genetic features in five
} patients

\author{
A Marco*1, I Calvo1, B Lopez ${ }^{1}$, JI Arostegui² and J Yagüe²
}

Address: ${ }^{1}$ Hospital Infantil la Fe, Valencia, Spain and ${ }^{2}$ Hospital Clinic, Barcelona, Spain

* Corresponding author

from $15^{\text {th }}$ Paediatric Rheumatology European Society (PreS) Congress

London, UK. 14-17 September 2008

Published: 15 September 2008

Pediatric Rheumatology 2008, 6(Suppl I):PI99 doi:I0.II86/I546-0096-6-SI-PI99

This abstract is available from: http://www.ped-rheum.com/content/6/SI/PI99

(C) 2008 Marco et al; licensee BioMed Central Ltd.

\section{Introduction}

The Hiper-IgD Syndrome (HIDS) is an autoinflammatory disease characterized by recurrent febrile episodes each 48 weeks accompanied by an intense inflammatory reaction, lymphadenopathy, abdominal pain, diarrhea, arthralgias, hepatosplenomegaly and cutaneous signs [1]. Mutations in the gene that codifies the enzyme mevalonate kinase (MVK), located in the chromosome 12q24, have been demonstrated to be the cause of this syndrome [2].

\section{Objective}

We describe the clinical and genetic findings of three families (five patients) with diagnosis of HIDS and confirmed mutational analysis.

\section{Methods}

We present a retrospective analysis of the patients and its genealogical tree. The mutational analysis was made by the service of Inmunology of the Hospital Clínic of Barcelona.

\section{Results}

Clinically the five patients presented the typical symptomatology with recurrent febrile episodes, intense abdominal pain (a case required several exploratory laparotomies), cervical lymphadenopathy, diarrhea and hepatosplenomegaly. One of the patients presented a chilotorax that resolved after discarding amiloidosis and initiating treatment. In all cases mutations I268T or V377I were detected. In two of the families, the parents demon- strated to be heterozygote carriers of one of the two found mutations.

All the patients have required steroids to high doses, nevertheless, three of the cases have developed steroid dependency with necessity of biological treatment with Anakinra, a recombinant, nonglycosylated synthetic form of the human interleukin-1 receptor antagonist (IL-1Ra), Kinere $^{\circledR}$ ) that in last publications has demonstrated to be the election treatment since the Hiper IgD Syndrome is part of the autoinflammatory diseases in whose common pathogenic mechanism the IL-1 takes part.

\section{References}

I. Aróstegui Jl, Yagüe J: Hereditary systemic autoinflammatory diseases. Hereditary periodic fever syndromes. Med Clin (Barc) 2007, I 29(7):267-77.

2. Haas D, Hoffmann GF: Mevalonate kinase deficiencies: from mevalonic aciduria to hyperimmunoglobulinemia $D$ syndrome. Orphanet J Rare Dis 2006, I:I3. 